http://dx.doi.org/10.32929/2446-8355.2020v29n1p118-129

\title{
INOCULAÇÃO E COINOCULAÇÃO COM Bradyhizobium japonicum E Azospirillum brasilense NA CULTURA DA SOJA
}

\author{
Leandro Meert ${ }^{*}$, Fernando Baise Fernandes ${ }^{2}$, Marcelo Marques Lopes Müller ${ }^{3}$, Diego Ary \\ Rizzardi ${ }^{4}$, Jhone de Souza Espindola ${ }^{5}$
}

\author{
${ }^{1}$ Eng. Agr. Dr., Docente do curso de Agronomia, Centro Universitário Integrado/Campo Mourão-PR. *E-mail do \\ autor correspondente: leandro.meert@ grupointegrado.br \\ ${ }^{2}$ Eng. Agr., AGD Bayer Cropscience, Peabiru-PR. \\ ${ }^{3}$ Eng. Agr. Dr., Docente do departamento de Agronomia, Universidade Estadual do Centro-Oeste \\ (UNICENTRO), Guarapuava-PR. \\ ${ }^{4}$ Eng. Agr. Dr., Melhorista, Limagrain, Londrina-PR. \\ ${ }^{5}$ Eng. Agr. Msc., Docente do curso de Agronomia, Centro Universitário Integrado, Campo Mourão-PR.
}

Recebido: 30/10/2018; Aceito: 25/03/2020

RESUMO: O objetivo deste trabalho foi avaliar o efeito da inoculação e coinoculação de sementes de soja com diferentes bactérias fixadoras de nitrogênio, associadas ou não à adubação nitrogenada, sobre os componentes de produção, produtividade e acúmulo de nitrogênio da cultura da soja. O delineamento experimental foi blocos casualizados, com quatro repetições, em esquema fatorial 4 x 2, avaliando-se sem inoculação, inoculação com Azospirillum brasilense, inoculação com Bradyrhizobium japonicum e inoculação com Azospirillum brasilense + Bradyrhizobium japonicum, e dois níveis de adubação nitrogenada: controle sem nitrogênio, adubação com $90 \mathrm{~kg} \mathrm{ha}^{-1}$. A maior altura de plantas foi verificada no tratamento com adição de $90 \mathrm{~kg} \mathrm{ha}^{-1}$ e sem nenhuma forma de inoculação. O número de vagens e o número de grãos por vagem não foram afetados pela adubação nitrogenada, mas foram significativamente maiores nos tratamentos com Bradyrhizobium japonicum e com a associação de Azospirillum brasilense + Bradyrhizobium japonicum. Na ausência da adubação nitrogenada, a produtividade de grãos foi superior com a coinoculação, e na presença de adubação nitrogenada a produtividade foi estatisticamente igual, sendo, portanto, a coinoculação sem adubação nitrogenada o melhor tratamento, devido ao menor custo. Houve um lucro $12 \%$ maior da coinoculação em relação a inoculação, sem a adubação nitrogenada.

Palavras-chave: Bactérias promotoras do crescimento de plantas. Fixação biológica. Nitrogênio. Simbiose.

\section{COINOCULATION WITH Bradyrhizobium japonicum AND Azospirillum brasilense ON SOYBEAN CROP}

\begin{abstract}
The objective of this work was to evaluate the effect of soybean co-inoculation with different nitrogen fixing bacteria, associated or not with nitrogen fertilization, on the components of yield, productivity and nitrogen extraction. The experimental design was randomized blocks with four replications, in a $4 \times 2$ factorial scheme, evaluating the non-
\end{abstract}


inoculation of the seeds, inoculation with Azospirillum brasilense, inoculation with Bradyrhizobium japonicum and inoculation with Azospirillum brasilense + Bradyrhizobium japonicum, and two levels of $\mathrm{N}$ fertilization: control without nitrogen, fertilization with $90 \mathrm{~kg}$ $\mathrm{ha}^{-1}$ of $\mathrm{N}$, being $20 \mathrm{~kg} \mathrm{ha}^{-1}$ at sowing and $70 \mathrm{~kg} \mathrm{ha}^{-1}$ in cover. The highest height of plants was verified in the treatment with addition of $90 \mathrm{~kg} \mathrm{ha}^{-1}$ and without any form of inoculation. The number of pods and the number of grains per pod were not affected by nitrogen fertilization, but were significantly higher in treatments with Bradyrhizobium japonicum and with the association of $A$. brasilense $+B$. japonicum. In the absence of nitrogen fertilization, grain yield was higher with co-inoculation, and in the presence of nitrogen fertilization the productivity was statistically the same, being therefore, the co-inoculation without nitrogen fertilization the best treatment, due to the lower cost. In the absence of nitrogen fertilization the highest nitrogen extraction was verified in the co-inoculation treatment.

Key words: Biological fixation. Nitrogen. Plant growth promoting bacteria. Symbiosis.

\section{INTRODUÇÃO}

A soja (Glycine max (L.) Merrill) é uma planta de ciclo anual originária do extremo Oriente, sendo a principal commodity do agronegócio brasileiro, representando $51 \%$ do total de grãos produzidos no Brasil. Na safra 2018/2019, a produção de soja foi de 114 milhões de megagramas, em 35,80 milhões de hectares, obtendo assim produtividade média de $3100 \mathrm{~kg}$ ha $^{-1}$, o estado do Mato Grosso é o maior produtor, responsável por $28 \%$ do total, seguido pelo Rio Grande do Sul, com 16\% da produção no Brasil, o Paraná é o terceiro com 14\% (COMPANHIA NACIONAL DE ABASTECIMENTO - CONAB, 2019).

$\mathrm{O}$ nitrogênio $(\mathrm{N})$ é o nutriente requerido em maior quantidade pela cultura da soja, que para produzir $1.000 \mathrm{~kg}$ de grãos necessita de, aproximadamente, $80 \mathrm{~kg}$ de N (HUNGRIA; CAMPOS; MENDES, 2001). O elemento é componente estrutural da clorofila, enzimas e proteínas, sendo também responsável por várias reações metabólicas essenciais (MARSCHNER, 2011).

A soja apresenta associação simbiótica com bactérias do gênero Bradyrhizobium, e desse modo não necessita de fertilização nitrogenada, pois as bactérias transformam o gás nitrogênio $\left(\mathrm{N}_{2}\right)$ atmosférico em amônia $\left(\mathrm{NH}_{3}{ }^{+}\right)$e o fornecem para a planta (MENDES et al., 2008). Estima-se que, no Brasil, as taxas de fixação biológica de N (FBN) na soja esteja entre 109 a $250 \mathrm{~kg} \mathrm{ha}^{-1}$, o que representa de 70 a $85 \%$ do total acumulado pela planta (HUNGRIA; CAMPOS; MENDES, 2001), Hungria et al. (2006) comentam que a FBN pode fornecer atém $94 \%$ do $\mathrm{N}$ requerido pela cultura da soja.

O constante lançamento de novas cultivares de soja com tetos produtivos elevados, combinados a resultados de pesquisa obtidos nos Estados Unidos e no Brasil, em que a soja tem respondido à aplicação de $\mathrm{N}$, voltaram a gerar dúvidas sobre a necessidade de adubar a soja com fertilizantes nitrogenados (MENDES et al., 2008; BARRANQUEIRO; DALCHIAVON, 2017; MORENO et al., 2018). 
Além das bactérias do gênero Bradyrhizobium, outros microrganismos podem proporcionar benefícios às culturas, e um dos grupos mais promissores são as bactérias promotoras do crescimento de plantas (BPCP), que por meio da produção de fitormônios e sacarídeos causam alterações fisiológicas nas plantas, além de também possuírem a capacidade de fixar N. As bactérias mais conhecidas deste grupo são as pertencentes ao gênero Azospirillum (CASSÁN; SALAMONE, 2008).

O estudo dessas bactérias foi realizado inicialmente em gramíneas, porém atualmente tem havido estudos de sua associação com bactérias do gênero Bradyrhizobium, em uma técnica conhecida como coinoculação (CHIBEBA et al., 2015), na cultura da soja. Essa combinação pode ser uma estratégia promissora para o aumento da produtividade, devido à combinação da FBN com a produção de fitormônios, a qual resulta em maior desenvolvimento radicular (HUNGRIA et al., 2015). Efeitos positivos sobre a produtividade da soja com o uso desta técnica já foram reportados por Schneider et al. (2017), Galindo et al. (2018).

Nesse contexto, o objetivo do presente trabalho foi verificar o efeito da inoculação (Bradyrhizobium) e coinoculação (Azospirillum + Bradyrhizobium) com bactérias fixadoras de $\mathrm{N}$, associadas ou não à adubação nitrogenada, sobre as características agronômicas da cultura da soja.

\section{MATERIAL E MÉTODOS}

O experimento foi conduzido no ano agrícola 2015/2016, no município de Campo

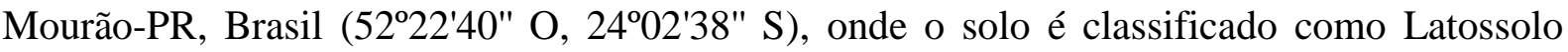
Vermelho distroférrico de textura muito argilosa (BHERING, 2007). A área do estudo está sob sistema de semeadura direta há mais de 20 anos, cultivando-se milho ou soja no verão e trigo ou aveia no inverno.

No inverno de 2015, para cobertura do solo, realizou-se o cultivo de aveia preta, o qual foi seguido da amostragem de solo $(0-20 \mathrm{~cm})$ para análise química, revelando as seguintes características próximo à semeadura da soja: $\mathrm{pH} \mathrm{CaCl} 2=5,7 ; \mathrm{H}+\mathrm{Al}(\mathrm{SMP})=4,06 \mathrm{cmol}_{\mathrm{c}} \mathrm{dm}^{-}$ 3. Matéria orgânica $=27,20 \mathrm{~g} \mathrm{dm}^{-3} ; \mathrm{P}($ Mehlich-I $)=21,65 \mathrm{mg} \mathrm{dm}^{-3} ; \mathrm{Ca}=4,98 \mathrm{cmol}_{\mathrm{c}} \mathrm{dm}^{-3} ; \mathrm{Mg}$ $=0,69 \mathrm{cmol}_{\mathrm{c}} \mathrm{dm}^{-3} ; \mathrm{K}=0,42 \mathrm{cmol}_{\mathrm{c}} \mathrm{dm}^{-3} ; \mathrm{e} \mathrm{V}=60 \%$.

O delineamento experimental adotado foi de blocos completos ao acaso, com quatro repetições, e tratamentos arranjados em esquema fatorial 4x2, estudando-se a inoculação com Azospirillum brasilense, com Bradyrhizobium japonicum, e a coinoculação com A. brasilense + B. japonicum, além de um controle sem inoculação. Também foram estudados dois níveis de adubação nitrogenada: sem $\mathrm{N}\left(0 \mathrm{~kg} \mathrm{ha}^{-1}\right.$ de $\left.\mathrm{N}\right)$ e com N (90 kg ha-1 de N).

Foram constituídas parcelas de 13,8 $\mathrm{m}^{2}$ (4,2 x 3,3 m), semeando-se a cultivar de soja Monsoy 5917 IPRO $^{\circledR}$, no espaçamento de $45 \mathrm{~cm}$ entre linhas e 14 sementes por metro, as quais foram tratadas com Piraclostrobina + Tiofanato metílico + Fipronil (100 g i.a. para cada $100 \mathrm{~kg}$ de semente). Os produtos utilizados para a inoculação e coinoculação foram o Masterfix gramíneas ${ }^{\circledR}\left(2 \times 10^{8} \mathrm{ufc} / \mathrm{ml}\right)$, com as estirpes Abv5 e Abv6 no caso do A. brasilense, e o Nitragin ${ }^{\circledR}\left(5 \times 10^{9} \mathrm{ufc} / \mathrm{ml}\right)$, no caso do B. japonicum. Nas duas inoculações, utilizou-se 
$200 \mathrm{ml}$ dos produtos por $100 \mathrm{~kg}$ de semente, e para a coinoculação utilizou-se a mistura dos dois produtos. Meia hora antes da semeadura fez-se a aplicação dos inoculantes, para isso pesou-se as sementes e as colocou em sacos plásticos e em seguida adicionou-se os inoculantes e homogeneizou a mistura.

A adubação de base foi realizada com $60 \mathrm{~kg} \mathrm{ha}^{-1}$ de $\mathrm{P}_{2} \mathrm{O}_{5}$ e $40 \mathrm{~kg} \mathrm{ha}^{-1}$ de $\mathrm{K}_{2} \mathrm{O}$, utilizando como fontes superfosfato simples e cloreto de potássio. Nos tratamentos onde havia a presença de nitrogênio a adubação foi parcelada em duas vezes, $20 \mathrm{~kg} \mathrm{ha}^{-1}$ na semeadura e $70 \mathrm{~kg} \mathrm{ha}^{-1}$ quando as plantas estavam em V4, utilizando como fonte de $\mathrm{N}$ a ureia.

O manejo fitossanitário foi realizado com produtos específicos para a soja, conforme recomendações técnicas para a cultura. Foram três aplicações de fungicidas, contemplando os produtos comerciais Tiofanato metílico (30 g i.a. ha $\left.{ }^{-1}\right)$, Trifloxistrobina + Protioconazol $(6+7$ g i.a. ha $\left.{ }^{-1}\right)$ e Picoxistrobina + Ciproconazol $\left(60+24\right.$ g i.a. ha $\left.{ }^{-1}\right)$. Os inseticidas utilizados foram Metomil (172 g i.a. ha ${ }^{-1}$ ), Acefato (900 g i.a. ha $\left.{ }^{-1}\right)$ e Imidacloprido + Beta-ciflutrina $\left(100+12,5\right.$ g i.a. ha $\left.{ }^{-1}\right)$, e os herbicidas foram Glifosato (960 g i.a. ha $\left.{ }^{-1}\right)$ e Cletodim (96 g i.a. $\left.\mathrm{ha}^{-1}\right)$. As informações sobre precipitação e temperatura durante o período experimental são apresentadas na Figura 1.

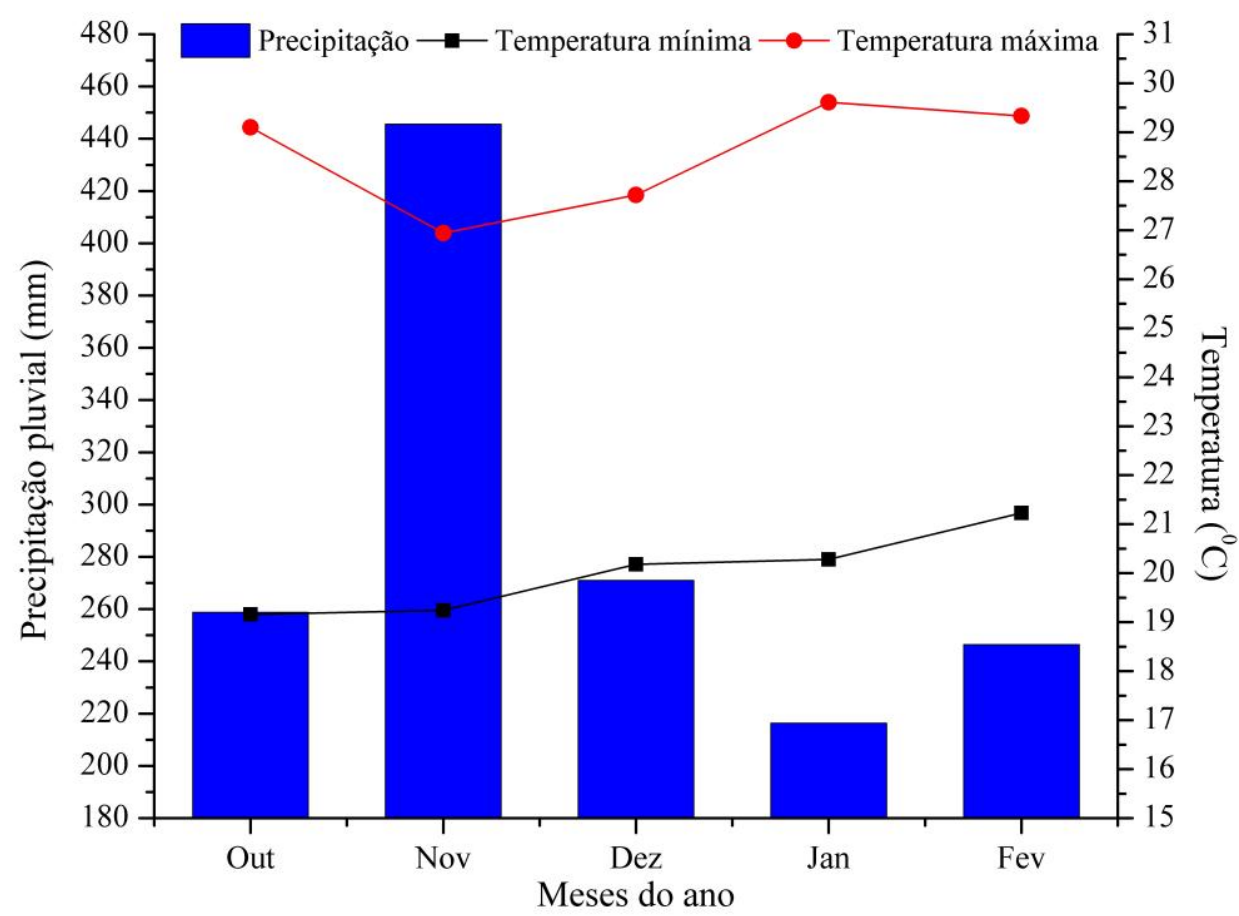

Figura 1. Precipitação pluvial $(\mathrm{mm})$ e temperaturas mínima e máxima $\left({ }^{\circ} \mathrm{C}\right)$ entre os meses de outubro de 2015 e fevereiro de 2016, registrados no município de Campo Mourão, Paraná, Brasil. Rainfall (mm), minimum and maximum temperatures $\left({ }^{\circ} \mathrm{C}\right)$ between October 2015 and February 2016, registered in the municipality of Campo Mourão, Paraná.

Fonte: Centro Universitário Integrado. Integado College.

Quando as plantas chegaram ao estádio de maturação fisiológica, avaliou-se: altura das plantas, diâmetro do caule, número de vagens por planta e número de grãos por vagem, sendo esses dados mensurados em 12 plantas na área central de cada parcela. A produtividade foi avaliada em 5 metros na mesma área central de cada parcela, colhendo-se manualmente as 
plantas, que posteriormente foram trilhadas em máquina estacionária. A massa dos grãos colhidos foi corrigida para umidade de $14 \%$, e a massa de mil grãos foi determinada segundo a Regra para análise de sementes (BRASIL, 2009). Alíquotas dos grãos colhidos em cada parcela foram moídas em moinho tipo Willey, para determinação do teor de $\mathrm{N}$ pelo método de Kjeldahl, conforme metodologia proposta por Malavolta et al. (1997).

Os dados obtidos foram submetidos à análise de variância e, em caso de significância dos tratamentos, as médias foram comparadas pelo teste de Tukey $(\mathrm{p} \leq 0,05)$, com o auxílio do pacote estatístico Sisvar (FERREIRA, 2014).

\section{RESULTADOS E DISCUSSÃO}

Sem a aplicação de $\mathrm{N}$, a inoculação ou coinoculação não promoveram alterações sobre a altura das plantas de soja. No entanto, com a aplicação de N, a ausência da inoculação propiciou aumento de $13 \%$ na altura das plantas de soja, em relação a média dos tratamentos inoculados. Sem realizar a prática da inoculação ou coinoculação, a aplicação de $\mathrm{N}$ favoreceu a altura das plantas de soja (Tabela 1).

Tabela 1. Altura média de plantas $(\mathrm{m})$, diâmetro médio do caule $(\mathrm{mm})$ e número médio de vagens por planta em função da inoculação da soja, com e sem adubação nitrogenada. Average plant height $(\mathrm{m})$, average stem diameter $(\mathrm{mm})$ and average number of pods per plant as a function of soybean inoculation, with and without nitrogen fertilization.

\begin{tabular}{lcc}
\hline Inoculante & \multicolumn{1}{c}{ Sem nitrogênio } & Com nitrogênio \\
\hline Sem inoculante & Altura de plantas $(\mathrm{m})$ & \\
A. brasilense & $0,87 \mathrm{bA}$ & $1,03 \mathrm{aA}$ \\
B. japonicum & $0,86 \mathrm{aA}$ & $0,90 \mathrm{aB}$ \\
A. brasilense + B. japonicum & $0,86 \mathrm{aA}$ & $0,89 \mathrm{aB}$ \\
& $0,90 \mathrm{aA}$ & $0,92 \mathrm{aB}$ \\
\hline Sem inoculante & Diâmetro do caule $(\mathrm{mm})$ & \\
A. brasilense & $6,09 \mathrm{aA}$ & $5,83 \mathrm{bB}$ \\
B. japonicum & $6,05 \mathrm{aA}$ & $6,30 \mathrm{aA}$ \\
A. brasilense + B. japonicum & $5,99 \mathrm{aA}$ & $5,87 \mathrm{aB}$ \\
& $6,10 \mathrm{aA}$ & $5,80 \mathrm{bB}$ \\
\hline Sem inoculante & Número de vagens por planta \\
A. brasilense & $64,80 \mathrm{aB}$ & $71,27 \mathrm{aA}$ \\
B. japonicum & $68,71 \mathrm{aAB}$ & $67,46 \mathrm{aA}$ \\
A. brasilense + B. japonicum & $72,68 \mathrm{aAB}$ & $74,53 \mathrm{aA}$ \\
\hline . & $79,94 \mathrm{aA}$ & $75,81 \mathrm{aA}$ \\
\hline
\end{tabular}

*Médias seguidas pela mesma letra minúscula na linha e maiúscula na coluna não diferem entre si pelo teste de Tukey a $\mathrm{p} \leq 0,05$. *Averages followed by the same lower case letter in the line and upper case in column do not differ by Tukey test at $p \leq 0.05$.

Fonte: Autoria própria. Own authorship.

Resultados similares foram verificados por Mundim et al. (2018) que não observaram efeito da coinoculação sobre a altura das plantas de soja, contudo, diferente do presente 
trabalho, os autores observaram efeito da inoculação com B. japonicum sobre a altura das plantas.

Silva et al. (2011) observaram maior altura de plantas e de inserção da primeira vagem quando aplicaram $24 \mathrm{~kg} \mathrm{ha}^{-1}$ de $\mathrm{N}$ na base associado ao B. japonicum em área de primeiro cultivo de soja. Parente et al. (2015) observaram maior altura de plantas quando houve aplicação de $40 \mathrm{~kg} \mathrm{ha}^{-1}$ de $\mathrm{N}$ na semeadura associado a inoculação com $B$. japonicum. Barranqueiro e Dalchiavon (2017) não observaram diferença na AP quando comparam aplicação de $\mathrm{N}$ (30 $\left.\mathrm{kg} \mathrm{ha}^{-1}\right)$ inoculação com B. japonicum e aplicação de $\mathrm{N}+$ inoculação com B. japonicum.

Quanto ao diâmetro de caule (DC), sem N também não houve efeito de inoculação, mas na presença do $\mathrm{N}$ a inoculação com $A$. brasilense resultou em DC maior que nos demais tratamentos, sem diferença entre eles. Quanto à adubação nitrogenada, nos tratamentos sem inoculação e com coinoculação a presença do N resultou em DC menor.

Cabe ressaltar que nos dois tratamentos em que o DC foi diminuído pela adubação N, houve aumento simultâneo da altura das plantas, sendo este aumento significativo no tratamento sem inoculante, indicando haver uma resposta das plantas em altura em detrimento do DC quando adubadas com $\mathrm{N}$, essa condição torna as plantas mais suscetíveis ao acamamento, condição que não é desejada em uma lavoura de soja, pois o acamamento além de reduzir a produtividade da soja, dificulta a aplicação de defensivos e a colheita (SOUZA et al., 2013).

Estudando soja e milho sob inoculação isolada e combinada com A. brasilense e $B$. japonicum, Cassán et al. (2009) encontraram resultados diferentes para a coinoculação, que resultou em aumento significativo da altura de plantas. Para o diâmetro do caule, os autores verificaram efeito da inoculação somente na presença da adubação nitrogenada, em que a inoculação com $A$. brasilense superou os demais tratamentos, o que concorda com os resultados obtidos no presente estudo

Sem N, o número de vagens por planta (NVP) foi maior com a coinoculação do que sem inoculação. Já na presença do N, não houve efeito dos níveis de inoculação sobre o NVP. Quanto à adubação nitrogenada, não houve efeito significativo do N sobre o NVP em nenhum nível de inoculação.

Bulegon et al. (2016) encontraram resultados distintos, verificando maior diâmetro do colo (cv. Turbo) no tratamento com nitrogênio sem inoculação em comparação aos tratamentos com inoculação e coinoculação. Para a cultivar CD 250, os autores não encontraram efeito dos tratamentos. Os autores também verificaram que o tratamento somente com adubação nitrogenada apresentou $53 \%$ a mais de vagens que a inoculação e a coinoculação. Concorre para essa discrepância de resultados a dose de $\mathrm{N}$ utilizada, de $240 \mathrm{~kg}$ $\mathrm{N} \mathrm{ha}^{-1}$ contra $90 \mathrm{~kg} \mathrm{~N} \mathrm{ha}^{-1}$ no presente estudo.

Os dados referentes ao número de grãos por vagem, massa de mil grãos, produtividade e extração de N pelos grãos de soja são apresentados na (Tabela 2). Sem o N, além de melhorar o NVP (tabela 1), a coinoculação resultou em maior (NGV). Com N, o NGV foi maior na 
inoculação com $B$. japonicum e na coinoculação, sem diferença entre ambos, em relação à inoculação com A. brasilense e sem inoculação, também sem diferença entre ambos.

No trabalho de Bulegon et al. (2016), o NGV não foi afetado pelos tratamentos, mostrando que diferenças de cultivar, dose de $\mathrm{N}$ estudada e outros fatores experimentais fazem variar as respostas à inoculação e coinoculação de microrganismos.

Tabela 2. Número de grãos por vagem, massa de mil grãos (g), produtividade $\left(\mathrm{kg} \mathrm{ha}^{-1}\right)$ e teor de nitrogênio em grãos de soja ( $\mathrm{g} \mathrm{kg}$ ) em função da inoculação da soja, com e sem adubação nitrogenada. Number of grains per pod, mass of one thousand grains $(\mathrm{g})$, productivity ( $\mathrm{kg} \mathrm{ha}$ $\left.{ }^{1}\right)$ and nitrogen content in soybean grains $(\mathrm{g} \mathrm{kg})$ as a function of soybean inoculation, with and without nitrogen fertilization.

\begin{tabular}{|c|c|c|}
\hline Inoculante & Sem nitrogênio & Com nitrogênio \\
\hline \multicolumn{3}{|c|}{ Número de grãos por vagem } \\
\hline Sem inoculante & $2,66 \mathrm{aB}$ & $2,66 \mathrm{aB}$ \\
\hline A. brasilense & $2,66 \mathrm{aB}$ & $2,67 \mathrm{aB}$ \\
\hline B. japonicum & $2,63 b B$ & $2,73 \mathrm{aA}$ \\
\hline A. brasilense $+B$. japonicum & $2,77 \mathrm{aA}$ & $2,76 \mathrm{aA}$ \\
\hline \multicolumn{3}{|c|}{ Massa de mil grãos (g) } \\
\hline Sem inoculante & $138 \mathrm{aAB}$ & $138 \mathrm{aB}$ \\
\hline A. brasilense & $134 \mathrm{aB}$ & $136 \mathrm{aB}$ \\
\hline B. japonicum & $140 \mathrm{aAB}$ & $141 \mathrm{aA}$ \\
\hline A. brasilense $+B$. japonicum & $143 \mathrm{aA}$ & $141 \mathrm{aA}$ \\
\hline \multicolumn{3}{|c|}{ Produtividade $\left(\mathrm{kg} \mathrm{ha}^{-1}\right)$} \\
\hline Sem inoculante & $3769,40 \mathrm{aB}$ & $3620,08 \mathrm{aB}$ \\
\hline A. brasilense & $3485,65 \mathrm{aB}$ & $3598,65 \mathrm{aB}$ \\
\hline B. japonicum & $3549,90 \mathrm{aB}$ & $3980,66 \mathrm{aA}$ \\
\hline A. brasilense $+B$. japonicum & $4009,56 \mathrm{aA}$ & $3947,98 \mathrm{aA}$ \\
\hline \multicolumn{3}{|c|}{ Acúmulo de nitrogênio pelos grãos de soja $\left(\mathrm{kg} \mathrm{ha}^{-1}\right)$} \\
\hline Sem inoculante & $183,84 \mathrm{aB}$ & $186,40 \mathrm{aC}$ \\
\hline A. brasilense & $184,86 b B$ & $195,56 \mathrm{aBC}$ \\
\hline B. japonicum & $184,87 \mathrm{bB}$ & $202,63 \mathrm{aAB}$ \\
\hline A. brasilense $+B$. japonicum & $213,07 \mathrm{aA}$ & $211,17 \mathrm{aA}$ \\
\hline
\end{tabular}

* Médias seguidas pela mesma letra minúscula na linha e maiúscula na coluna não diferem entre si pelo teste de Tukey a $\mathrm{p} \leq 0,05$. *Averages followed by the same lower case letter in the line and upper case in column do not differ by Tukey test at $p \leq 0.05$.

Fonte: Autoria própria. Own authorship.

A massa de mil grãos (MMG) foi maior com a coinoculação, diferindo da inoculação com A. brasilense na ausência de N. De forma similar ao que ocorreu com o NGV e o NVP, esses resultados mostram que os efeitos benéficos da coinoculação sem a adubação nitrogenada se concentraram na fase reprodutiva da soja, melhorando os componentes produtivos das plantas, sem afetar aos atributos de crescimento da cultura.

Com a adubação nitrogenada presente, a MMG também respondeu de forma similar ao ocorrido para o NGV, sendo maior na inoculação com B. japonicum e na coinoculação em relação à inoculação com $A$. brasilense e sem inoculação, indicando haver melhor adaptação 
do B. japonicum que do A. brasilense à presença do N. Outro indício desse comportamento é que o único efeito da adubação nitrogenada ocorreu na inoculação isolada de B. japonicum, em que a presença o $\mathrm{N}$ aumentou a $\mathrm{MMG}$.

Quanto à produtividade, sem $\mathrm{N}$ a resposta foi similar ao ocorrido para $\mathrm{NGV}$, sendo que a coinoculação resultou em produtividade maior (12\%) que nos demais tratamentos de inoculação, sem diferença entre si. Estes resultados podem ser devidos aos efeitos combinados das duas bactérias aumentando o número de nódulos (AUNG et al., 2013) e a massa dos nódulos nas raízes (BENINTENDE et al., 2010), bem como o comprimento a e massa das raízes da soja (CASSÁN et al., 2009). Chibeba et al. (2015) verificaram em seus estudos que a coinoculação resulta na nodulação precoce, aportando $\mathrm{N}$ mais cedo às plantas.

$\mathrm{Na}$ presença do $\mathrm{N}$, a resposta seguiu os comportamentos do NGV e MMG, sendo maior na inoculação com $B$. japonicum e na coinoculação que nos demais tratamentos. A presença do $\mathrm{N}$, entretanto, não afetou significativamente a produtividade em nenhum dos níveis de inoculação, sendo que o tratamento somente com adição de nitrogênio produziu $4 \%$ a mais que o controle sem inoculação e sem N.

A inoculação com $B$. japonicum e a coinoculação quando em associação com a adubação nitrogenada apresentaram produtividade superior a inoculação com A. brasilense e a testemunha, porém esta produtividade não foi superior àquela obtida com as bactérias somente (sem adubação nitrogenada).

Saikia et al. (2010) comentam que grande parte do efeito da coinoculação é em virtude das alterações morfológicas que o A. brasilense causa nas raízes da soja, dessa forma a planta tende a produzir mais, pois suas raízes se tornam maiores e o aporte de $\mathrm{N}$ às plantas também é maior, conforme pode ser verificado no presente trabalho, onde o tratamento com a coinoculação na ausência da adubação nitrogenada exportou mais $\mathrm{N}$ para os grãos que os demais tratamentos (Tabela 2).

Cassán e Salamone (2008) comentam que o A. brasilense pode melhorar a resposta das plantas a déficits hídricos, devido a sua ação sobre o comprimento das raízes. Como no presente estudo as condições climáticas foram favoráveis (Figura 1), é possível que as respostas da cultura à coinoculação sejam mais expressivas em anos agrícolas posteriores, em que a disponibilidade hídrica não seja tão boa.

Aratani et al. (2008) trabalhando com uma dose de $90 \mathrm{~kg} \mathrm{ha}^{-1}$ de $\mathrm{N}$ aplicado em uma só vez ou parcelado e inoculação com B. japonicum também não encontraram efeito dos tratamentos sobre a produtividade. Barranqueiro e Dalchiavon (2017) não observaram ganhos na produtividade quando compararam inoculação $+30 \mathrm{~kg}^{\mathrm{de}} \mathrm{N} \mathrm{ha}^{-1}$ aplicados na base com a inoculação de B. japonicum.

Hungria et al. (2013), em dois anos agrícolas e quatro locais, Londrina e Ponta Grossa no Paraná, onde já havia populações de Bradyrhizobium, e Rio Verde e Cachoeira Dourada em Goiás, onde não havia populações de Bradyrhizobium, observaram que, em todos os locais, a coinoculação resultou em produtividade superior à inoculação isolada de Bradyrhizobium e igual ao uso de $200 \mathrm{~kg} \mathrm{ha}^{-1}$ de $\mathrm{N}$ tratamento sem inoculante. 
Mendes et al. (2008) no Cerrado, realizaram vários ensaios e concluíram que a suplementação com fertilizantes nitrogenados na cultura da soja é economicamente inviável e que portanto é necessário aprimorar cada vez mais o processo de fixação biológica para que ele possa suprir as crescentes demandas da cultura em virtude dos constantes acréscimos na produtividade, Salvagiotti et al. (2008) citam que a fertilização nitrogenada na cultura na soja somente será necessária se houver alguma restrição à fixação biológica.

Por outro lado, Mundim et al. (2018) não observaram ganhos de produtividade com a coinoculação, quando a comparam com a inoculação com B. japonicum, os autores atribuíram o resultado a uma possível competição entre os microrganismos.

O resultado do presente trabalho vai de encontro a afirmação de Mendes et al. (2003) que diz não haver necessidade de uma dose de arranque com fertilizante nitrogenado em áreas de plantio direto ou convencional.

$\mathrm{Na}$ ausência da adubação nitrogenada, a coinoculação obteve produtividade superior (450 $\mathrm{kg} \mathrm{ha}^{-1}$ ) a inoculação com B. japonicum, o custo da inoculação por hectare na região é de $\mathrm{R} \$ 28,00$ e o preço da saca de soja $\mathrm{R} \$ 70,81$ (17/09/2019), com base nestes dados pode-se observar que o tratamento com a coinoculação gerou um ganho de $\mathrm{R} \$ 503,07$ por hectare quando comparado a inoculação com B. japonicum, mostrando ser uma prática economicamente viável para os produtores rurais.

Em contrapartida, a aplicação de $\mathrm{N}$ não é viável economicamente, pois os tratamentos que receberam a adubação não produziram mais que os tratamentos que não receberam (Tabela 2), pois além do custo do fertilizante, o produtor rural terá que fazer a aplicação em cobertura e isso acarretará em mais um custo.

Estes dados corroboram com os resultados de Galindo et al. (2018) que ao avaliarem a inoculação e coinoculação em duas cultivares de soja obtiveram rendimento de aproximadamente $600 \mathrm{~kg} \mathrm{ha}^{-1}$ a mais que a inoculação e lucro $14,1 \%$ maior. Schneider et al. (2017) obtiveram margem líquida superior a inoculação com B. japonicum independente da dose utilizada.

O tratamento com a coinoculação e sem adubação nitrogenada foi o que acumulou mais nitrogênio nos grãos $\left(213,07 \mathrm{~kg} \mathrm{ha}^{-1}\right)$, quando houve a associação com adubação nitrogenada verificou-se diferença somente entre a coinoculação e a testemunha. Estes dados indicam que a associação das duas bactérias proporciona um aporte maior de nitrogênio para as plantas e para as condições testadas isso resultou em maior produtividade.

\section{CONCLUSÃO}

Como a adubação nitrogenada influenciou pouco o crescimento e os componentes produtivos, e não afetou a produtividade em nenhum tratamento de inoculação, não se recomenda esta prática na cultura da soja nas condições avaliadas.

Para as condições testadas a coinoculação é uma prática recomendada pois proporciona produtividade superior a inoculação. 


\section{REFERÊNCIAS BIBLIOGRÁFICAS}

ARATANI, R. G.; LAZARINI, E.; MARQUES, R. R.; BACKES, C. Adubação nitrogenada em soja na implantação do sistema plantio direto. Bioscience Journal, Uberlândia, v. 24, n. 3, p.31-38, 2008.

AUNG, T. T.; TITTABUTR, P.; BOONKER, N.; HERRIDGE, D.; TEAUMROONG, N. CoInoculation Effects of Bradyrhizobium japonicum and Azospirillum sp. on Competitive Nodulation and Rhizosphere Eubacterial Community Structures of Soybean under RhizobiaEstablished Eoil Conditions. African Journal of Biotechnology, Nairobi, v. 12, n. 2, p.28502862, 2013.

BARRANQUEIRO, H. R.; DALCHIAVON, F. C. Aplicação de azoto na cultura da soja. Revista de Ciências Agrárias, v. 40, n. 1, p.196-204, 2017.

BENINTENDE, S.; UHRICH, W.; HERRERA, M.; GANGGE, F.; STERREN, M.; BENINTENDE, M. Comparación entre Coinoculación con Bradyrhizobium japonicum y Azospirillum brasilense e Inoculación simple con Bradyrhizobium japonicum en la Nodulación, Crecimiento y Acumulación de N en el Cultivo de Soja. Agriscientia, Córdoba, v. 27, n. 2, p.71-77, 2010.

BHERING, S. B.; SANTOS, H. G.; MANZATTO, C. V.; BOGNOLA, I.; FASOLO CARVAlHO, A. P.; POTTER, O.; AGLIO, M. L. D.; SIlVA, J. S.; CHAFFIN, C. E.; CARVALHO JUNIOR, W. Mapa de Solos do Estado do Paraná. Rio de Janeiro: Embrapa Solos, 2007, 73p. (Documentos, 96).

BRASIL. MINISTÉRIO DA AGRICULTURA, PECUÁRIA E ABASTECIMENTO MAPA. Regras para Análise de Sementes. Brasília: Mapa/ACS, 2009. 395 p.

BULEGON, L. G. L.; RAMPIM, L.; KLEIN, J.; KESTRING, D.; GUIMARÃES, V. F.; BATTISTUS, A. G.; INAGAKI, M. Componentes de produção e produtividade da cultura da soja submetida à inoculação de Bradyrhizobium e Azospirillum. Terra Latinoamericana, Chapingo, v. 34, n. 2, p.169-176, 2016.

CASSÁN, F. D.; SALAMONE, I. G.. Azospirillum sp.: cell physiology, plant interactions and agronomic research in Argentina. Buenos Aires: Asociación Argentina de Microbiologia, 2008. 268 p.

CASSÀN, F.; PERRIG, D.; SGROY, V.; MASCIARELlI, O.; PENNA, C.; LUNA, V. Azospirillum brasilense Az39 and Bradyrhizobium japonicum E109, Inoculated Singly or in Combination, Promote Seed Germination and Early Seedling Growth in corn (Zea mays L.) and Soybean (Glycine max L.). European Journal of Soil Biology, Braunschweig, v. 45, n. 1, p.28-35, 2009.

COMPANHIA NACIONAL DE ABASTECIMENTO - CONAB. Acompanhamento da safra brasileira de grãos. Brasília: CONAB, 2019. 47 p.

CHIBEBA, A. M.; GUIMARÃES, M. F.; BRITO, O. R.; NOGUEIRA, M. A.; ARAUJO, R. S.; HUNGRIA, M. Co-inoculation of soybean with Bradyrhizobium and Azospirillum 
promotes early nodulation. American Journal of Plant Science, v. 6, n. 10, p.1641-1649, 2015.

FERREIRA, D. F. Sisvar: a guide for its bootstrap procedures in multiple comparisons. Ciência e Agrotecnolgia, Lavras, v. 38, n. 2, p.109-112, 2014.

GALINDO, F. S.; TEIXEIRA FILHO, M. C. M.; BUZETTI, S.; LUDKIEWICZ, M. G. Z.; ROSA, P.; TRITAPEPE, C. A. Technical and economic viability of co-inoculation with Azospirillum brasilense in soybean cultivars in the Cerrado. Revista Brasileira de Engenharia Agrícola e Ambiental, Campina Grande, v. 22, n. 1, p.51-56, 2018.

HUNGRIA, M.; CAMPO, R. J.; MENDES, I. C. Fixação biológica de nitrogênio na cultura da soja. Londrina: Embrapa Soja, 2001. 48 p. (Embrapa Soja. Circular Técnica, 35; Embrapa Cerrados. Circular Técnica, 13).

HUNGRIA, M.; FRANCHINI, J. C.; CAMPO, R. J.; CRISPINO, C. C.; MORAES, J. Z.; SIBALDELLI, R. N.; ARIHARA, J. Nitrogen nutrition of soybean in Brazil: contributions of biological N2 fixation and N fertilizer to grain yield. Canadian Journal of Plant Science, Ottawa, v. 86, n. 4, p.927-939, 2006.

HUNGRIA, M.; NOGUEIRA, M. A.; ARAUJO, R. S. Co-Inoculation of Soybeans and Common Beans with Rhizobia and Azospirilla: Strategies to Improve Sustainability. Biology and Fertility of Soils, Heidelberg, v. 49, n. 7, p.791-801, 2013.

HUNGRIA, M.; NOGUEIRA, M. A.; ARAUJO, R. S. Soybean Seed Co-Inoculation with Bradyrhizobium spp. and Azospirillum brasilense: A New Biotechnological Tool to Improve Yield and Sustainability. American Journal of Plant Sciences, local, v. 6, n. 6, p.811-817, 2015.

MARSCHNER, H. Mineral Nutrition of Higher Plants. 3 ed. San Diego: Academic Press, 2011. $651 \mathrm{p}$.

MALAVOlTA, E.; VITTI, G. C.; OLIVEIRA, S. A. Avaliação do estado nutricional das plantas. Piracicaba: Potafos. 1997. 319 p.

MENDES, I. C.; HUNGRIA, M.; VARGAS, M. A. T. Soybean response to starter nitrogen and Bradyrhizobium inoculation on a Cerrado Oxisol under no-tillage and conventional tillage systems. Revista Brasileira de Ciência do Solo, Viçosa, v. 27, n. 1, p.81-87, 2003.

MENDES, I. C.; REIS JUNIOR, F. B.; HUNGRIA, M.; SOUSA, D. M. G.; CAMPO, R. J. Adubação nitrogenada suplementar tardia em soja cultivada em Latossolos do cerrado. Pesquisa Agropecuária Brasileira, Brasília, v. 43, n. 8, p.1053-1060, 2008.

MORENO, G.; ALBRECHT, A. J. P.; PIEROZAN JUNIOR, C.; PIVETTA, A. T.; TESSELE, A.; LORENZETTI, J. B.; FURTADO, R. C. N. Application of nitrogen fertilizer in high-demand stages of soybean and its effects on yield performance. Australian Journal of Crop Science, Camberra, v. 12, n. 1, p.16-21, 2018. 
MUNDIM L. M. F.; ROCHA, D. K.; REIS, C. F.; CARVALHO, E. R. Coinoculação de Azospirillum brasilense e Bradyrhizobium via sementes de soja no cerrado. Global science and technology, Rio Verde, v. 11, n. 3, p.10-19, 2018.

PARENTE, T. L.; LAZARINI, E.; CAIONI, S.; PIVETTA, R. S.; SOUZA, L. G. M.; BOSSOLANI, J. W. Adubação nitrogenada em genótipos de soja associada à inoculação em semeadura direta no Cerrado. Revista Brasileira de Ciências Agrárias, Recife, v.10, n. 2, p.249-255, 2015.

SAIKIA, S. P.; DUTTA, S. P.; GOSWAMI, A.; BHAUS, B. S.; KANJILAL, P. B. Role of Azospirillum in the Improvement of Legumes. In: KHAN, M. S., ZAIDI, A., MUSARRAT, J. Microbes for Legume Improvement. Wien: Springer-Verlag, 2010. p. 389-408.

SALVAGIOTTI, F.; CASSMAN, K. G.; SPECHT, J. E.; WALTERS, D. T.; WEISS, A.; DOBERMANN, A. Nitrogen uptake, fixation and response to fertilizer $\mathrm{N}$ in soybeans: A review. Field Crops Research, Amsterdã, v. 108, n. 1, p.1-13, 2008.

SCHNEIDER, F.; PANIZZON, L. C.; SORDI, A.; RESCHKE, C.; CERICATO, A.; KLEIN, C. Eficiência agronômica da cultura da soja (Glycine max (L.) Merril) submetida a coinoculação. Revista scientia agraria, Curitiba, v 18, n. 4, p.72-79, 2017.

SILVA, A. F.; CARVAlHO, M. A. C.; SCHONINGER, E. L.; MONTEIRO, S.; CAIONE, G.; SANTOS, P. A. Doses de inoculante e nitrogênio na semeadura da soja em área de primeiro cultivo. Bioscience Journal, Uberlândia, v. 27, n. 3, p.404-412, 2011.

SOUZA, C. A.; FIGUEIREDO, B. P.; COELHO, C. M. M.; SANGOI, L. Arquitetura de plantas e produtividade da soja decorrente do uso de redutores de crescimento. Bioscience Journal, Uberlândia, v. 29, n. 3, p.634-643, 2013. 